\title{
Multimodal Integration of Self-Motion Cues in the Vestibular System: Active versus Passive Translations
}

\author{
Jerome Carriot, Jessica X. Brooks, and Kathleen E. Cullen \\ Department of Physiology McGill University, Montreal, Quebec H3G 1Y6, Canada
}

The ability to keep track of where we are going as we navigate through our environment requires knowledge of our ongoing location and orientation. In response to passively applied motion, the otolith organs of the vestibular system encode changes in the velocity and direction of linear self-motion (i.e., heading). When self-motion is voluntarily generated, proprioceptive and motor efference copy information is also available to contribute to the brain's internal representation of current heading direction and speed. However to date, how the brain integrates these extra-vestibular cues with otolith signals during active linear self-motion remains unknown. Here, to address this question, we compared the responses of macaque vestibular neurons during active and passive translations. Single-unit recordings were made from a subgroup of neurons at the first central stage of sensory processing in the vestibular pathways involved in postural control and the computation of self-motion perception. Neurons responded far less robustly to otolith stimulation during self-generated than passive head translations. Yet, the mechanism underlying the marked cancellation of otolith signals did not affect other characteristics of neuronal responses (i.e., baseline firing rate, tuning ratio, orientation of maximal sensitivity vector). Transiently applied perturbations during active motion further established that an otolith cancellation signal was only gated in conditions where proprioceptive sensory feedback matched the motor-based expectation. Together our results have important implications for understanding the brain's ability to ensure accurate postural and motor control, as well as perceptual stability, during active self-motion.

Key words: corollary discharge; efference copy; head motion; neuron; otolith; proprioception

\section{Introduction}

In everyday life, our perception of self-motion depends on the integration of both visual and nonvisual cues, including vestibular and proprioceptive information. During passively applied linear motion, the visual system provides retinal-image motion (optic flow) cues, whereas the otolith organs of the vestibular system encode linear acceleration. For instance, common activities, such as taking an elevator and standing on an escalator or moving walkway, result in activation of the vestibular receptor cells of the saccule and utricle, respectively. The self-motion information available during voluntary translation is even more multifaceted because extra-retinal information is provided not only by the vestibular system, but also by the proprioceptive sensors of the muscles, tendons, and joints, which sense the relative position of neighboring parts of the body. Additionally, motorcommand related information could potentially be integrated with other existing information to contribute to the brain's estimate of self-motion.

Although it has been long appreciated that patterns of image motion simulating translation provide forceful sensations of dis-

Received July 15, 2013; revised 0ct. 30, 2013; accepted Nov. 2, 2013.

Author contributions: J.C. and K.E.C. designed research; J.C., J.X.B., and K.E.C. performed research; J.C. and K.E.C. analyzed data; J.C. and K.E.C. wrote the paper.

This study was supported by CIHR, NIH, and FRQNT. We thank Mohsen Jamali, Diana Mitchell, and Alexis Dale for critically reading the paper, and S. Nuara and W. Kucharski for excellent technical assistance.

Correspondence should be addressed to Dr Kathleen E. Cullen, McIntyre Medical Research Building, Room 1219, 3655 Prom Sir William 0sler, Montreal, QC, Canada H3G 1Y6. E-mail: kathleen.cullen@mcgill.ca.

DOI:10.1523/JNEUROSCI.3051-13.2013

Copyright $\odot 2013$ the authors $\quad 0270-6474 / 13 / 3319555-12 \$ 15.00 / 0$ placement (Gibson, 1950), it is now recognized that extra-visual cues alone can make important contributions to self-motion perception. In the absence of visual cues, humans use vestibular (otolith) information to estimate passive linear displacement (Guedry and Harris, 1963; Israël and Berthoz, 1989; Mittelstaedt and Glasauer, 1991; Israël et al., 1993, 1997; Berthoz et al., 1995; Ivanenko and Grasso, 1997; Grasso et al., 1999). Additionally, there is compelling evidence that proprioceptive and/or motorrelated signals contribute to the estimation of self-motion during voluntary movements. For example, estimates of distance traveled and self-velocity are more reliable when displacement is the result of locomotion (i.e., active translation) than when subjects are passively displaced (Becker et al., 2002; Jürgens and Becker, 2006; Frissen et al., 2011). Furthermore, although vestibular neurectomy patients are able to perform active translation tasks with the same accuracy as control subjects, their performance remains subpar during passive motion tasks (Worchel, 1952; Glasauer et al., 1994, 2002).

A key question yet to be answered is how does the brain integrate otolith, proprioceptive, and motor-related signals during active self-motion? To address this question we recorded from single neurons at the first stage of central vestibular processing. Although otolith afferents robustly encode head acceleration during active and passive translation (Jamali et al., 2009), we found that a specific class of their target neurons, termed vestibular-only (VO) neurons, showed a marked reduction in their responses to active translations. To understand the underlying mechanism, we controlled the relationship between in- 
tended and actual movement and found that an otolith cancellation signal was generated only when activation of neck proprioceptors matched the motor-generated expectation. Our results reveal that a distinction in the coding of active and passive translation occurs at the earliest stages of vestibular processing as a result of the integration of otolith, proprioceptive, and motor efference copy information. Importantly, when active and passive motions are experienced simultaneously, this distinction only occurs if the proprioceptive feedback produced by active motion is not altered by concurrent passive motion.

\section{Materials and Methods}

Two male rhesus monkeys (Macaca mulatta) were prepared for chronic extracellular recording using aseptic surgical techniques. All experimental protocols were approved by the McGill University Animal Care Committee and were in compliance with the guidelines of the Canadian Council on Animal Care.

\section{Surgical procedures}

Anesthesia protocols and surgical procedures have been previously described by Roy and Cullen (2001a). Briefly, under surgical levels of isoflurane (2-3\% initially, and $0.8-1.5 \%$ for maintenance) an eye coil was implanted behind the conjunctiva, and a dental acrylic implant was fastened to the animal's skull using stainless steel screws. The implant held in place a stainless steel post used to restrain the animal's head and a stainless steel recording chamber to access the medial vestibular nucleus. Animals were given 2 weeks to recover from the surgery before any experiments were performed.

\section{Data acquisition}

During experiments, monkeys sat comfortably in a primate chair fixed to a linear sled which was mounted on a rotational servomotor, thereby providing the ability to apply (1) translation along any direction in the horizontal plane and (2) rotation about an earth-vertical axis. Extracellular single-unit activity was recorded using tungsten microelectrodes (Frederick-Haer), and gaze and head angular positions were measured using the magnetic search coil technique as detailed previously (Brooks and Cullen, 2009). Linear head and body acceleration were measured in three dimensions using 3-D linear accelerometers (ADXL330Z, Analog Devices), which were firmly attached to the animal's head post and chair frame, respectively. The unit activity, eye, head, and body signals from each experimental session were recorded on digital audiotape for later playback. During playback, each unit's isolation was carefully evaluated and action potentials were discriminated using a windowing circuit (BAK Electronics). Eye, head, and body signals were low-pass filtered at $250 \mathrm{~Hz}$ (8 pole Bessel filter) and sampled at $1 \mathrm{kHz}$. All the apparatus and data displays were controlled on-line by a UNIX-based real-time dataacquisition system (REX; Hayes et al., 1982).

\section{Behavioral paradigms}

Monkeys were trained to visually follow a target (HeNe laser) projected, via a system of two galvanometer controlled mirrors, onto a cylindrical screen located $60 \mathrm{~cm}$ away. The location of the vestibular nucleus was confirmed relative to that of the abducens nucleus; a structure easily identified based on its stereotypical discharge patterns during eye movements (Cullen and McCrea, 1993; Sylvestre and Cullen, 1999). Once localized, recordings were made from single vestibular nuclei neurons during an initial battery of paradigms designed to identify neurons that responded in a manner consistent with previous characterizations of a subclass of neurons termed VO neurons, which are sensitive to passive vestibular stimulation (rotation, Scudder and Fuchs, 1992; translation, Dickman and Angelaki, 2002) but are insensitive to eye movements ( $n=$ 54). First, each neuron's sensitivity to passively applied linear acceleration was confirmed by translating the monkey (head and body together in space) on the sled along the naso-occipital or interaural axes $(1 \mathrm{~Hz}$, $\pm 0.2 \mathrm{G}$ ) in complete darkness. If a neuron responded to translation along at least one axis, we next tested its sensitivity to angular velocity by rotating the monkey in yaw using the vestibular servomotor $(1 \mathrm{~Hz}, \pm 40 \%$ s). Finally, we confirmed that neurons were insensitive to eye movements by recording their activity during ocular fixation, saccades $\left( \pm 30^{\circ}\right)$, and pursuit motion $(0.5 \mathrm{~Hz}, 40 \%$ seak velocity). Only cells that did not exhibit any eye-velocity or eye-position sensitivity were further studied with the stimuli outlined in the following text.

Passive translations. Neural sensitivities were next more extensively characterized in three different paradigms, in which passive translations were applied along the naso-occipital and interaural axes $(4 \mathrm{~Hz}, 0.2 \mathrm{~g} ; \mathrm{g}=$ $9.81 \mathrm{~m} / \mathrm{s}^{2}$ ). First, the monkey, head and body together, was sinusoidally translated along the linear sled. This paradigm, termed "passive wholebody translation," was used to characterize responses to passive vestibular stimulation only. Second, another sled attached to the monkey's head was used to apply passive sinusoidal translation of the head relative to the stationary body. This paradigm, termed "passive head-on-body translation," produced simultaneous stimulation of both proprioceptive and vestibular sensors. Third, the monkey's head was held stationary relative to the earth while its body was translated underneath. This paradigm, termed "passive body-under-head translation," was used to characterize neuronal responses to dynamic stimulation of the neck proprioceptors.

Self-generated and attempted translations. After a given neuron had been characterized during the three passive translational motion paradigms described above, we slowly and carefully released the brake of the linear sled thereby allowing the monkey to make voluntary head translations along the naso-occipital or interaural axes. If the neuron remained well isolated $(n=$ 35 ), we then characterized its responses while the monkeys made voluntary head translations. Specifically, monkeys were trained to generate voluntary sinusoidal head translations in each of the two permitted directions (i.e., naso-occipital and interaural) to track a presented food target. These selfgenerated voluntary head movements were characterized by peak accelerations of $\sim 0.2 \mathrm{~g}$ and predominant frequencies between 3 and $4.5 \mathrm{~Hz}$ (average $3.8 \pm 0.7 \mathrm{~Hz}$ ). Notably, the stimulus was matched during both active and passive paradigms to facilitate comparison.

To test whether the presence of motor commands to the neck musculature altered neuronal responses we recorded from a subgroup of neurons $(n=21)$ when the monkey attempted to follow the same food target while its head was unexpectedly restrained. The concurrent neck linear force produced against the head restraint was recorded using a load cell transducer (Omegadyne). Note that single trials with unexpected head restraint $(\sim 10 \%)$ were randomized between trials in which monkeys freely made unrestrained active translations so that the monkey was not able to anticipate the restraint.

Combined passive and active translations. Finally, for neurons that continued to remain well isolated $(n=10)$ we used two additional paradigms to test how neurons encode vestibular stimulation resulting from passive and active translations that occur simultaneously. In the first paradigm, the monkey voluntarily translated its head (relative to its earth fixed body) in one direction while undergoing concurrent passive whole-body translation along the same axis. In this condition, the active and passive components of head translation were comparable to those described above. In the second paradigm, we applied a brief stereotyped transient perturbation $(80 \mathrm{~ms}, 0.27 \pm$ $0.05 \mathrm{~g}$ ) to the head sled. This perturbation was first applied when the animal was not moving to characterize the cell's response to the passive stimulus alone. Then we applied this same passive stimulus while the monkey actively translated its head on body. Note that single trials in which we applied unexpected head transients were randomized $(\sim 10 \%)$ between trials in which monkeys freely made unrestrained active translations so that the monkey was not able to anticipate this stimulus.

To isolate the active component of motion in the combined condition, we computed the average perturbation waveform, computed $>50$ head perturbation motions applied when the monkey was stationary, and subtracted this trajectory (synchronized relative to perturbation onset) from the recorded head acceleration (note that to verify that the head perturbation was consistent in both conditions, we compared the impact on the load cell transducer when the head perturbation was applied alone and during active motion $(1.57 N \pm 0.03$ vs $1.57 N \pm 0.06 ; p<0.001)$.

\section{Analysis of neuronal discharges}

Data were imported into the Matlab (MathWorks) programming environment for analysis. Head acceleration signals were digitally low-pass filtered at 

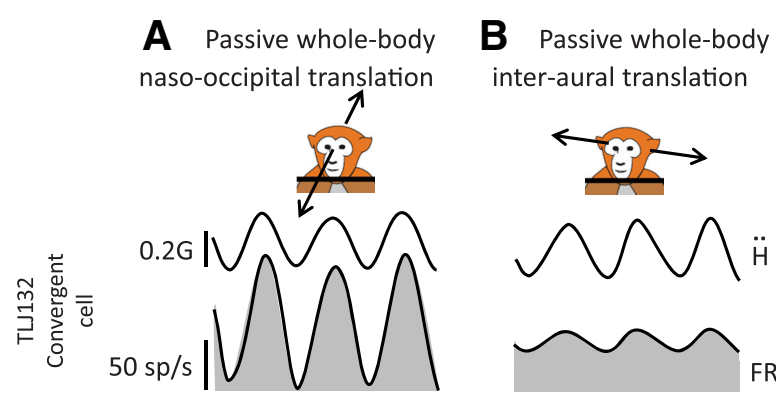
inter-aural translation

\section{Tuning curve / maximal sensitivity}
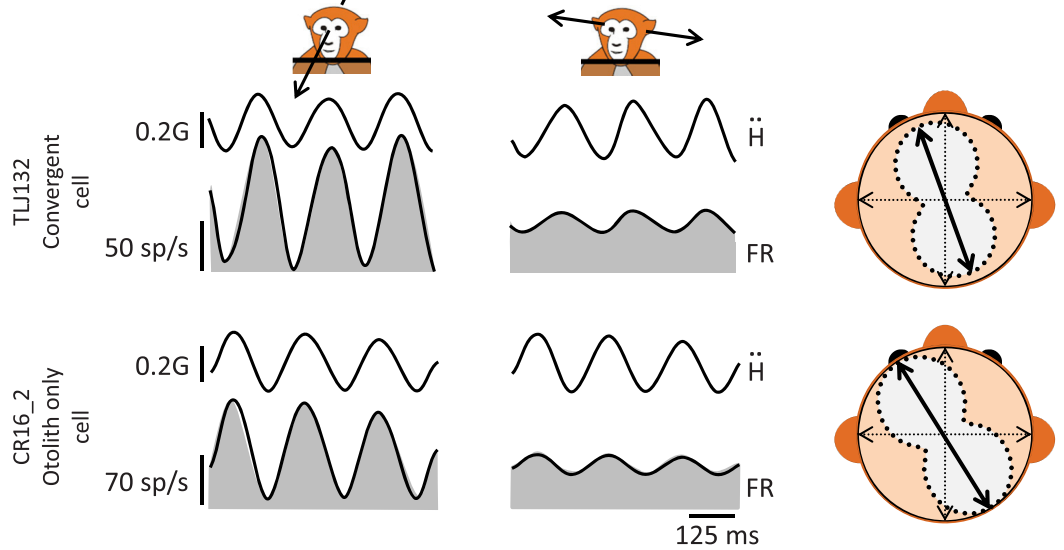

Figure 1. Activity of two example neurons (unit TU132: convergent cell and unit CR16_2: otolith only cell) during passive whole-body naso-occipital translation $(\boldsymbol{A})$ and interaural translation $(\boldsymbol{B})$. A head movement based model (Eq. 1; solid black trace) is superimposed on the firing rate traces. $\boldsymbol{C}$, The spatial sensitivity of the neuron: tuning curve (dashed line around the gray area) and maximal sensitivity vector (thick arrow). Ḧ, Head acceleration; FR, firing rate.

$30 \mathrm{~Hz}$. Estimates of the time-dependent firing rate were obtained by low-pass filtering the spike train using a Kaiser window with cutoff frequency greater than that of the stimulus by $1 \mathrm{~Hz}$ (Cherif et al., 2008). The resting discharge of each unit was determined from $\sim 10 \mathrm{~s}$ of unit activity collected while the animal was stationary with its head restrained. To verify that a neuron was unresponsive to eye position and/or velocity, periods of steady fixation and saccade-free smooth pursuit were analyzed using a multiple regression analysis (Roy and Cullen, 1998, 2001b).

To quantify each unit's response to translation, we then used leastsquared regression analysis:

$$
\hat{f r}=b+S v \dot{H}(t)+S a \ddot{H}(t),
$$

where $\hat{f r}$ is the estimated firing rate, $S v$ and $S a$ are coefficients representing sensitivities to head velocity and acceleration respectively, $b$ is a bias term representing the resting discharge, and $\dot{H}(t)$ and $\ddot{H}(t)$ are head velocity and head acceleration, respectively. Then to evaluate the model's ability to estimate neuronal firing rate, the variance-accounted-for (VAF) was computed:

$$
V A F=1-[\operatorname{var}(\hat{f r}-f r) / \operatorname{var}(f r)],
$$

where $f r$ represents the actual firing rate, and a VAF of 1 indicates a perfect fit to the data (Cullen et al., 1996). Note that the VAF in such a linear model is equivalent to the square of the correlation coefficient $\left(R^{2}\right)$. Note that only data for which the firing rate was $>10 \mathrm{sp} / \mathrm{s}$ were included in the optimization to prevent fitting a given neuron's response during epochs where it was driven into cutoff. The coefficients in Equation 1 were then used to determine each cell's head acceleration sensitivity $[(\mathrm{sp} / \mathrm{s}) / \mathrm{G}]$ and phase with respect to head acceleration $(\varphi)$ using the following equations (Sadeghi et al., 2007, 2009):

$$
\begin{gathered}
S=\sqrt{\left[S_{a}^{2}+\left(2 \pi f S_{v}\right)^{2}\right]} \\
\varphi=\operatorname{atan}\left(\frac{2 \pi f S_{v}}{S_{a}}\right) \times \frac{180}{\pi} .
\end{gathered}
$$

For neurons that were tested in both directions (naso-occipital and interaural) a gain and phase "tuning curve" was computed at each frequency (Angelaki, 1993) by the following equation:

$$
f r(t)=b+S(\propto) \cos (\omega t+\varphi(\propto))
$$

where

$$
\begin{aligned}
S(\propto) & =\left[S_{i a}^{2} \cos ^{2} \propto+S_{n o}^{2} \sin ^{2} \propto\right. \\
& \left.+2 S_{i a} S_{n o} \sin \propto \cos \propto \cos (\Delta \varphi)\right]^{1 / 2}
\end{aligned}
$$

and

$\tan \varphi(\propto)$

$$
=\frac{\mathrm{S}_{\mathrm{ia}} \cos \propto \sin \varphi_{i a}+\mathrm{S}_{\mathrm{no}} \sin \propto \sin \varphi_{\mathrm{no}}}{\mathrm{S}_{\mathrm{ia}} \cos \propto \cos \varphi_{i a}+\mathrm{S}_{\mathrm{no}} \sin \propto \cos \varphi_{\mathrm{no}}} .
$$

$S(\propto)$ is the neuronal sensitivity to a stimulus oriented with an arbitrary angle $\propto, \varphi(\propto)$ is the phase shift for the angle $\propto, S_{i a}$ is the sensitivity of this neuron along the interaural axis, $S_{n o}$ is the sensitivity of this neuron along the naso-occipital axis and $\Delta \varphi$ is the difference between $\varphi_{i a}$ and $\varphi_{n o}$, the phase shift of the neuronal response to the stimulation along the interaural and naso-occipital axis respectively. The semimajor axis of this tuning curve $\left(S_{\max }\right)$ represents the neuron's maximum sensitivity axis and the semiminor axis $\left(S_{\text {min }}\right)$ represents its minimum sensitivity axis. A measure of this two-dimensional sensitivity is the tuning ratio, defined as the gain ratio of the minimum over the maximum sensitivity of the cell (Angelaki, 1993).

Note that because our stimuli were designed not to drive the neurons beyond their linear range (i.e., cutoff or saturation), neuronal sensitivities to acceleration and deceleration should be comparable. We confirmed this by estimating neuronal sensitivities during both acceleration and deceleration phases of the head movement for our population of $\mathrm{VO}$ cells during passive whole-body rotation. Sensitivities to acceleration and deceleration were $227 \pm 26(\mathrm{sp} / \mathrm{s}) / \mathrm{G}$ versus $234 \pm 24(\mathrm{sp} / \mathrm{s}) / \mathrm{G}$ were comparable $(p=0.38)$. Accordingly, below we use the term "maximal vector orientation" to refer to the orientation of the maximal sensitivity vector relative to the naso-occipital axis.

The SE is presented and statistical significance was determined using Student's $t$ tests.

\section{Results}

Recordings were made from a distinct population of vestibular nuclei neurons, termed VO neurons, based on their responses to passive vestibular stimulation and insensitivity to eye movement (Scudder and Fuchs, 1992; Cullen and McCrea, 1993; McCrea et al., 1999). Notably, these neurons receive vestibular afferent input, and their outputs mediate postural reflexes as well as perception and computation of movement (for review, see Cullen, 2011, 2012). Single-unit recordings were made from VO neurons $(n=54)$ while head-restrained monkeys were passively moved, head and body together, relative to space. We focused our analysis on 35 of these neurons for which isolation successfully maintained during active head movements, and of which $37 \%$ responded to only translation (otolith only neurons) and 64\% responded to both translation and yaw rotation [convergent (i.e., otolith + canal) neurons]. Responses from a typical convergent and typical otolith only neuron are shown in Figure $1 A, B$. Both neurons responded to naso-occipital (Fig. $1 A$ ) and interaural translation (Fig. $1 B$ ), but the depth of modulation was stronger for naso-occipital translation. Figure $1 C$ illustrates the tuning curves and maximal sensitivity vectors (see Materials and Methods) for each example neuron $\left[S_{\max }: 386\right.$ versus $444(\mathrm{sp} / \mathrm{s}) / \mathrm{G}$, with maximal sensitivity vector oriented 20 vs $32^{\circ}$ relative to the nasooccipital axis, respectively].

On average, response sensitivity and phase (relative to head acceleration) was comparable for our samples of convergent and otolith only neurons [average sensitivity $224 \pm 10.9$ vs $221 \pm 12.1$ 
$(\mathrm{sp} / \mathrm{s}) / \mathrm{G}, p=0.47$; average phase $-27.8 \pm$ $9^{\circ}$ versus $\left.-30.7 \pm 12^{\circ}, p=0.42\right]$. Convergent neurons, by definition, also responded to yaw rotations in the horizontal plane [average sensitivity $0.4 \pm 0.2(\mathrm{sp} / \mathrm{s}) /(\mathrm{deg} / \mathrm{s})$; average phase: $4 \pm 20^{\circ}$ relative to head velocity]. There was no systematic relationship between a given convergent neuron's sensitivity to translation and its sensitivity to yaw rotations $(p=0.24)$. Finally, consistent with prior classifications of these neurons during passive vestibular stimulation (Fuchs and Kimm, 1975), the two example cells in Figures 1, like all neurons in our sample, were unresponsive to eye position during steady fixation, saccadic eye movements, and smooth pursuit.

\section{Response during voluntary head-on-body motion}

To establish whether and how extravestibular cues influence neuronal responses during active translational self-motion, we next recorded neuronal responses during actively generated translations. Once a given neuron's passive vestibular (translational and yaw rotation) sensitivities had been fully characterized in the head-restrained condition as described above (Fig. 1), we released the restraint to allow the monkey freedom to voluntarily translate its head either along the naso-occipital or interaural axes over the possible natural range. During the critical transition between head-restrained and headunrestrained conditions, the waveform of the action potential of each neuron was carefully monitored to ensure that the cell remained undamaged and well isolated (see Materials and Methods).

In striking contrast to their robust sensitivity to passive translations (Fig. 1), neurons were markedly less responsive to voluntary head translations. Figure 2 shows examples of the reduced modulation to active translations for the same two example neurons shown in Figure 1. Notably, although each neuron strongly responded to passive naso-occipital translation, both were relatively unresponsive to comparable actively generated naso-occipital translation. We quantified this attenuation by assessing whether a model based on each neuron's passive head acceleration sensitivity along aiven axis (Eq. 1) could predict its firing rate during active translation along the same axis (Fig. 2A,B, blue line). The response gains during voluntarily translations along both axes were strongly attenuated (Fig. $2 A, B$, compare blue and black lines superimposed on the firing rates), corresponding to $82 \%$ versus $59 \%$ (naso-occipital) attenuation, and $67 \%$ versus $49 \%$ (interaural) attenuation for the example convergent and otolith-only neurons, respectively. Consequently, each neuron's maximal sensitivity was also significantly reduced during active movements ( $76 \%$ and $57 \%$ attenuation, respectively; Fig. 2 , compare red and blue ellipses).

Across our population of neurons, responses during active head translations were, on average, 61.4\% ( \pm 3.7) attenuated, relative to those predicted by the sensitivity to passive-translation (Fig. $3 A$, inset; $p=0.0004$ ). This can be seen in the plot shown in Figure $3 A$, which compares each neuron's response sensitivity in both conditions. Notably, data from all neurons fall below the unity line indicating that the modulation of each neuron in our sample was attenuated during active head-on-body translations as compared with passive whole-body translations (slope $=0.32$; $R^{2}=0.12$ ). Moreover, on average, the level of attenuation during active translation was comparable for translations along the naso-occipital and interaural axes $(p=0.28)$, and was not significantly different across convergent and otolith-only neuron subpopulations $(p=0.37)$. Thus, unlike otolith sensory afferents that show comparable modulation in response to linear acceleration during passive and active head translations (Jamali et al., 2009), neuronal responses at the first central stage of otolith processing differentially encode active and passive translation.

Notably, although neuronal sensitivities to translation were suppressed during active translation, this attenuation was not accompanied by corresponding changes in a given neuron's spontaneous discharge, maximal vector orientation (i.e., preferred orientation), or tuning ratio. First, as is shown in Figure $3 B$, the baseline firing rate around which responses were modulated remained constant regardless of whether movements were passively or actively generated (slope $=0.96, R^{2}=0.95$, where the slope is not significantly different from $1, p=0.9$ ). Additionally, the orientation of a given neuron's maximal sensitivity vector was unchanged across conditions ( $p=$ 0.72 , for the population). During active motion the preferred orientation of our population remained slightly biased within $\pm 30^{\circ}$ of the interaural axis ( $44 \%$ vs $56 \%$ of cells for the passive condition; Fig. $3 C$, left). Overall, the overrepresentation of lateral tuning observed in both conditions was consistent with prior passive characterizations (Angelaki and Dickman, 2000; Dickman and Angelaki, 2002). Quantification of neuronal tuning ratios (see Materials and Methods) also revealed that they remained consistent for passively and actively generated movements (Fig. 3C, center, compare blue $(0.40 \pm 0.05)$ and red $(0.49 \pm 0.05)$ bars $(p=0.32)$. Finally, to quantify the overall change in preferred orientation, we took the difference between each neuron's maximal vector orientation computed for active translation and that computed for passive translation and found no significant difference relative to zero (Fig. 3C, right, black bar). 
A Cell sensitivity during active vs passive translation

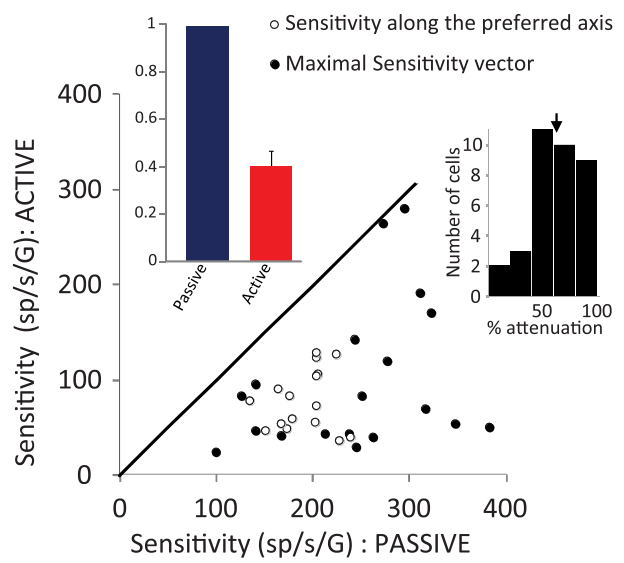

B Bias during active and passive translation

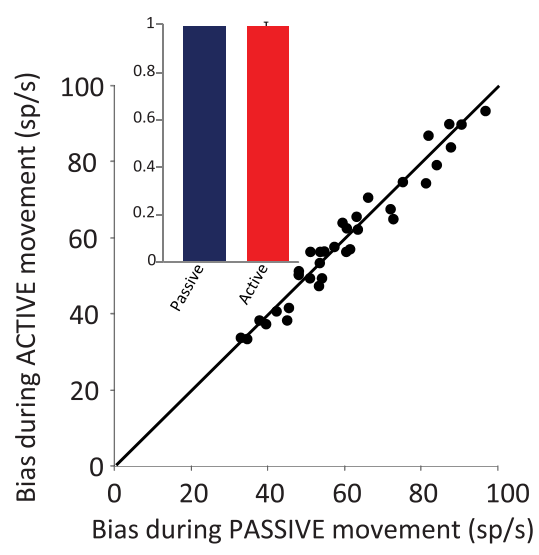

C Tuning ratio and direction of the maximal sensitivity vector

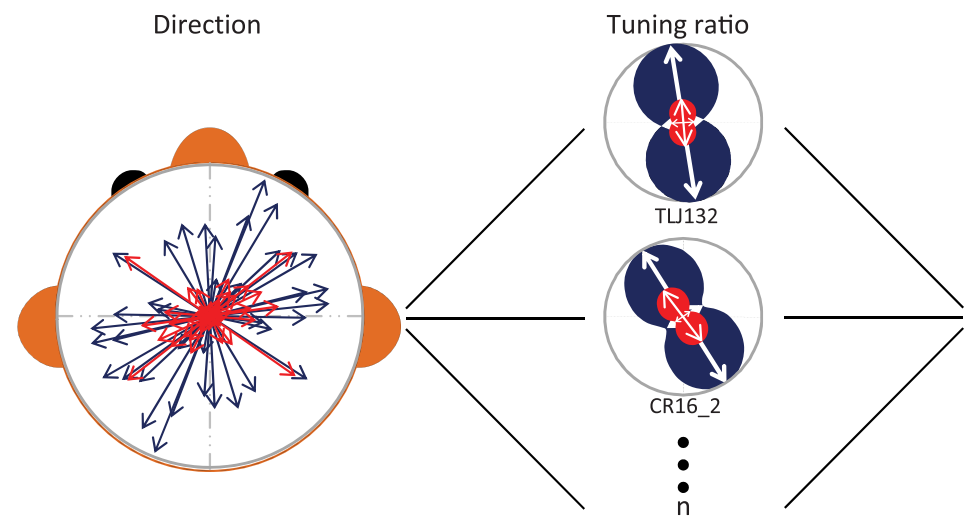

Average
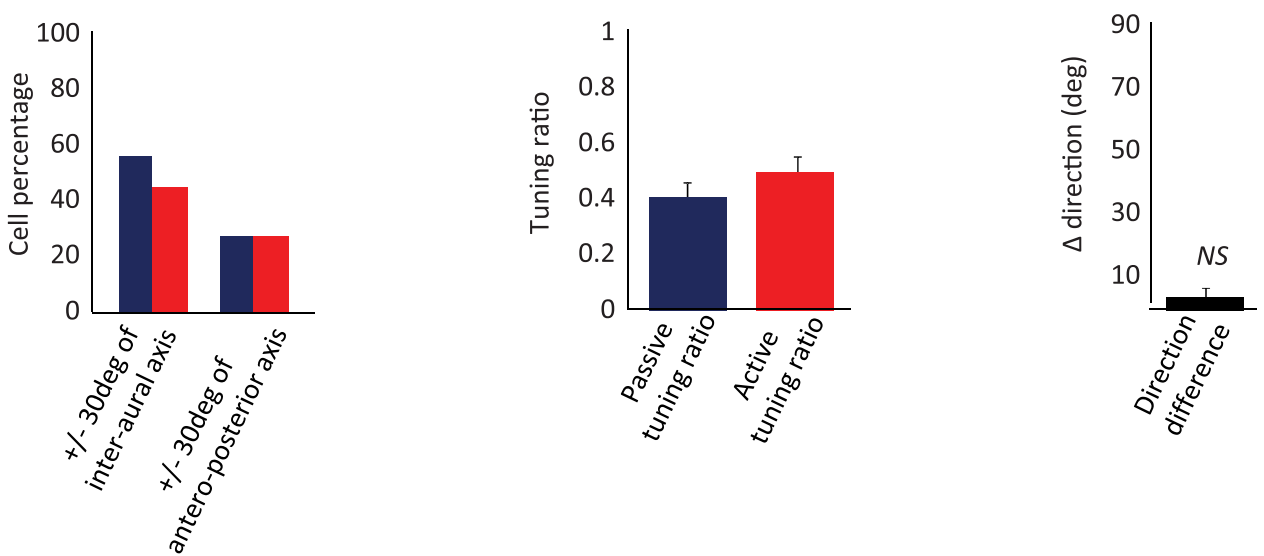

Figure 3. Responses to active versus passive translation: population summary. $\boldsymbol{A}$, Neuronal sensitivities to passive whole-body versus active head-on-body translations. Filled circles represent the neurons for which we were able to compute the maximal sensitivity vector $(n=18)$, whereas open circle represent the sensitivity of the cells tested along their preferred major axis (naso-occipital or interaural axis). Note that all data points fall below the unity line, demonstrating a relative reduction in sensitivity to active translation. Left, Inset, Mean neuronal sensitivities to self-generated head motion (red) normalized to whole-body sensitivity (blue) further illustrate the attenuation in response. Right, Inset, Distribution histogram showing each neuron's percentage attenuation. $\boldsymbol{B}$, Comparison of the resting bias estimated for neuronal responses revealed no significant difference for the same two conditions. Inset, Mean resting bias estimated during self-generated head motion (red) normalized to resting bias estimated during whole-body translation (blue). $\boldsymbol{C}$, Comparison of maximal vector orientation and tuning ratio for passive whole-body and active head-on-body translations. Left, The spatial distribution of the maximal sensitivity vector for passive (blue) and the active motion (red) across the neuronal population. Left, Bottom, The mean repartition of the maximal vector orientation around the interaural axis and the naso-occipital axis. The tuning ratio (ratio between the maximal and the minimal sensitivity) for two example cells is presented in the middle. Population average of the tuning ratio does not differ for passive (blue) and self-generated (red) head movement stimulation conditions (middle, bottom). To further compare passive and active motion, maximal sensitivity vectors for active motion were normalized in magnitude and orientation relative to those computed during passive motion (right). The population average is represented on the right panel. Neither the tuning ratio nor the orientation of the maximal sensitivity vector differed for passive (blue) and self-generated (red) head-movement stimulation conditions. Population average of the difference in preferred orientation is presented below (right, bottom). 


\section{Mechanisms of otolith cancellation}

Neck proprioceptive input does not directly suppress otolith input Given that otolith afferents similarly encode active and passive translations (Jamali et al., 2009) it follows that the robust afferent input to the vestibular nuclei neurons during active translation is cancelled by extra-vestibular signal(s). Notably, the results shown so far quantified neuronal responses to passive motion by applying the stimulus that has been most commonly used to quantify vestibular responses to translation, namely motion of the whole body (i.e., head and body together) through space. However, under the conditions for which we studied active head translation, the brain has access to additional information about self-motion as a result of both proprioceptive inputs that are produced by activation of the neck musculature (i.e., head-on-body movements) and the motor command that generates the active head-on-body motion. Accordingly, although vestibular receptors were similarly stimulated during the passive and active translation conditions, the two additional extra-vestibular cues available during active movement could play an important role in attenuating neuronal responses to active self-motion. To test this proposal, we performed a series of experiments to examine whether and how self-motion information available from these other sources could contribute to suppressing the translational responses of central vestibular neurons during active movements.

First, to test whether neck proprioceptive stimulation produced by head-on-body motion could potentially be used to support the attenuation of responses to vestibular otolith input during translations, we passively translated the animal's head to produce comparable motion relative to its body. Specifically, if neck afferent inputs serve to selectively reduce the vestibularly driven modulation of neurons, then we would have expected to see response attenuation during the simultaneous stimulation of the otoliths and neck proprioceptors. This prediction was contradicted by our quantification of neuronal responses; neuronal sensitivities to translation were comparable during passive whole-body and passive head-on-body motion. Figure $4 A$ shows the responses of an example neuron (Figs. 1, 2, the convergent neuron) during passive head-on-body translations. There was excellent correspondence between the response of the neuron and the prediction (thick black trace) computed from its translational sensitivity during whole-body motion. The histogram and plot in the bottom of Figure $4 A$ summarizes these results for the population of neurons. Notably, across the population translational sensitivities were comparable in both conditions [247 \pm 26.4 vs $249 \pm 33.4(\mathrm{sp} / \mathrm{s}) / \mathrm{G}$ for whole-body translation versus head-on-body translation respectively, $p=0.81$ ], In addition, comparison on a cell-by-cell basis revealed that each neuron's response was comparable in both conditions; all data points fell near the unity line and the slope of the regression line to the data were not different from unity $(p=0.78)$.

To further confirm that neurons do not respond to passive stimulation of neck proprioceptors, we next recorded from single neurons during a second paradigm in which proprioceptive stimulation was delivered in isolation by passively translating the monkey's body beneath its earth-stationary head (see Materials and Methods). Figure $4 B$ illustrates the response recorded from the same example neuron. Notably, the neuron did not respond to the passive stimulation of neck proprioceptors, and continued to fire at its spontaneous discharge rate (Fig. $4 B$, thick trace). Accordingly, the neuron's response was poorly predicted by a negative image of its response to vestibular stimulation (Fig. $4 B$, dashed trace). Note that we scaled the negative image by $60 \%$ to correspond to the modulation that would be expected for this neuron if the direct activation of proprioceptors had cancelled the vestibular responses during active head-on-body motion (Fig. 2, top). Figure $4 B$ (bottom) summarizes the sensitivity of our population of neurons during dynamic (sinusoidal) bodyunder-head translations; mean translational sensitivities were negligible $[7.78(\mathrm{sp} / \mathrm{s}) / \mathrm{G} \pm 14$ compare light gray bar to the dashed bar representing the neck modulation theoretically required to attenuate the otolith responses during active translation; $n=35$ ].

Thus together, the findings of our experiments in which passive neck stimulation was applied either simultaneously with corresponding vestibular stimulation (Fig. $4 A$ ) or in isolation (Fig. $4 B$ ) show that the activation of the neck proprioceptors does not directly contribute to the reduction of neuronal sensitivity to otolith input during active translations.

\section{Neck proprioceptive motor commands do not directly suppress otolith input}

As noted above, during active movements, self-motion information is not only provided by the resulting activation of the vestibular system and proprioceptive sensors, but is also available to the brain by means of the motor command that is generated to produce the movement. Accordingly, we next tested whether motor efference copy signals might contribute to the reduction of translational sensitivity during active movements. To date, previous studies have not measured the linear force produced during attempted movements when a monkey's head was restrained. Thus, we first confirmed that the linear forces generated in this condition were comparable to those measured during active head movements, by applying a brake mid-motion $(1.8 \mathrm{~N} \pm 0.8$ vs $1.67 \mathrm{~N} \pm 0.6$ for the head restraint condition).

The linear force trajectories and unit responses measured during attempted translations are shown for the example neuron in Figure $4 C$. Unit responses along naso-occipital axis, aligned on the onset of force, are shown separately for forward (Fig. 4C, right; linear force: $1.75 \mathrm{~N} \pm 0.3$ ) versus backward (Fig. $4 C$, left; $1.9 \mathrm{~N} \pm 0.6)$ translations. If motor efference copy signals produce an inhibitory drive to reduce neuronal response to active otolith stimulation, then firing rates should be modulated during the generation of linear force (i.e., a measure of the motor efference copy signal). However, this was not the case as can be seen by comparison of firing rate and the same scaled negative image shown in Figure $4 B$ (Fig. $4 C$, superimposed dashed trace). Indeed, regardless of force direction, the firing rates remained constant and unchanged from baseline. Similar results were obtained for each neuron tested in our sample [mean sensitivity: 3.4 $(\mathrm{sp} / \mathrm{s}) / \mathrm{G} \pm 17, p=0.76 ; n=21]$. Accordingly, the generation of a motor command signal does not directly contribute to the reduction of neuronal sensitivity to otolith input during active translations (black bar, Fig. $4 C$, bottom, compare black bar to the dashed bar representing the modulation theoretically required to attenuate the otolith responses during active translation).

Otolith input suppression during active translation requires a match between expected and actual neck proprioceptive input Together, the above results show that neurons were neither responsive to passive stimulation of neck proprioceptors alone nor to the generation of a neck efference copy signal. Thus, the attenuation of otolith signals cannot be explained by a simple cue combination and is likely the result of a more complex computation. Notably, in the experiment shown in Figure $4 C$ the head 
A Passive Head-on-body translation

Vestibular +

Proprioceptive stimulation
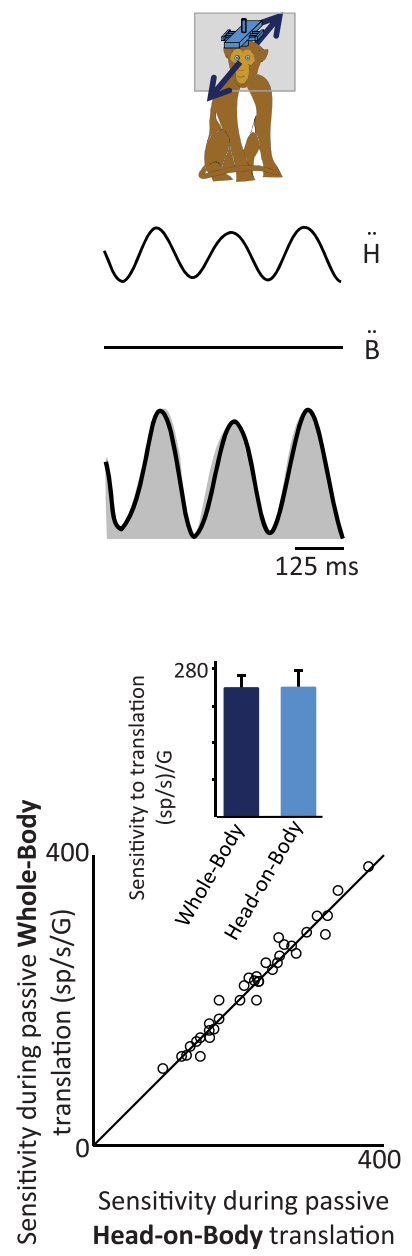

$(\mathrm{sp} / \mathrm{s} / \mathrm{G})$ B Passive Body-under-head
translation

Proprioceptive stimulation
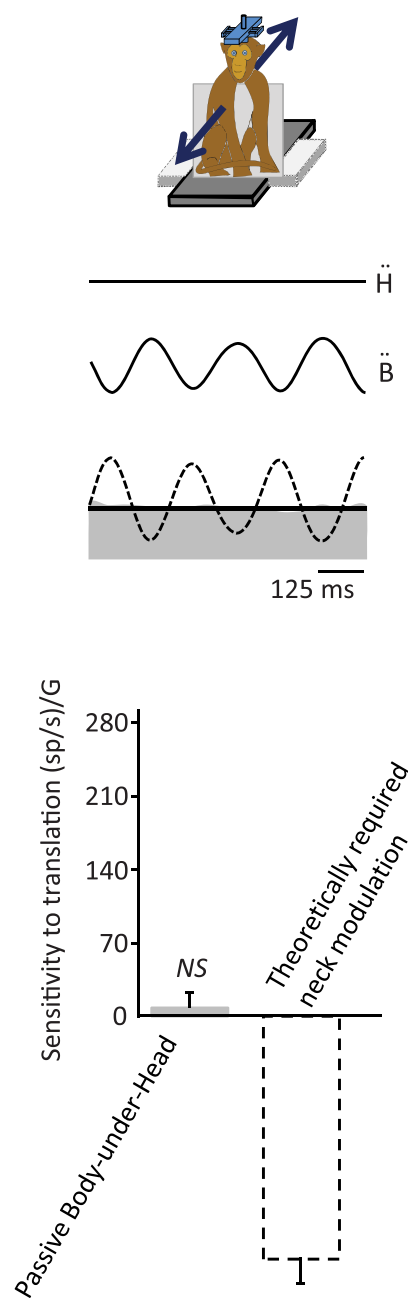

\section{Attempted Head-on-body} translation

Efference copy signal
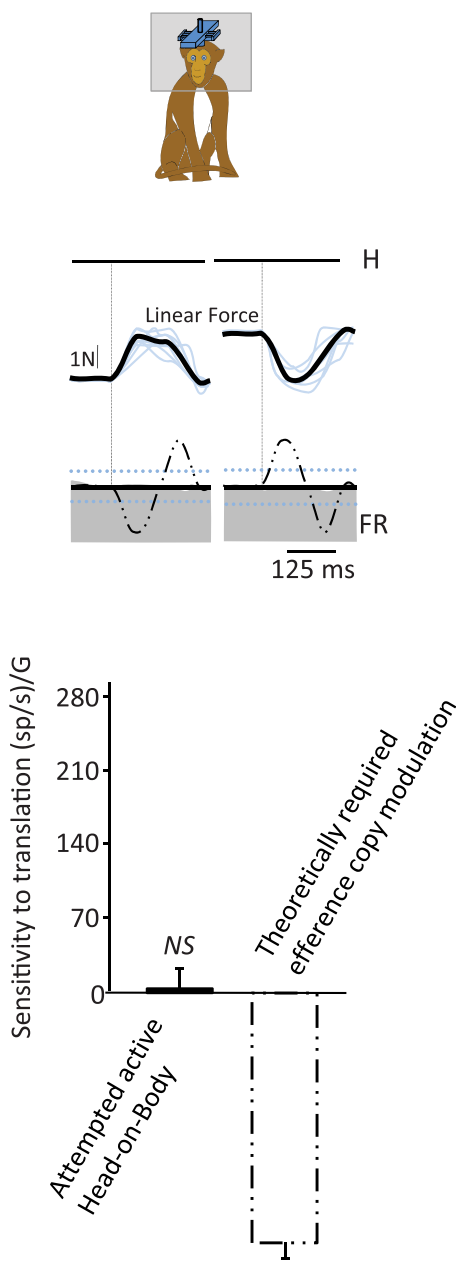

Figure 4. Neurons are not responsive to either the passive stimulation of proprioceptors or the generated efference copy signals in the absence of corresponding head motion. $\boldsymbol{A}$, An example neuron's response to combined passive, vestibular and proprioceptive stimulation (head-on-body translation; cell TL132; Figs. 1-3). Superimposed on the neuronal firing rate (FR) is the best estimate of the neuronal response (thick black trace). Bottom, Scatter plot showing each neuron's sensitivity to passive whole-body-translation versus passive head-on-body translation. Inset, Bar graph compares population averages for sensitivities to passive whole-body-translation (dark blue) and passive head-on-body translation (light blue). No difference in sensitivity was observed in these two conditions. $\boldsymbol{B}$, The same example neuron's response to neck proprioceptive stimulation: the body was sinusoidally translated under the stationary head. Superimposed on the neuronal FR is the best estimate of the neuronal response (thick black trace) and a prediction based on the neck modulation that would be theoretically required to account for the attenuation in response observed during active head-on-body motion (dashed line). Bottom, Bar graph summarizes population averaged neuronal sensitivities as well as the average of this latter theoretical prediction. $\boldsymbol{C}$, The same neuron's response when motor commands are generated in the absence of corresponding head motion (attempted head-on-body translation). The linear force produced by the monkey's neck is shown by the blue traces. Superimposed on the neuronal FR is the best estimate of the neuronal response (thick black trace) and a prediction based on a motor efference copy-driven modulation that would be theoretically required to account for the attenuation in response observed during active head-on-body motion (dashed black line). All neurons were unresponsive to the production of motor efference copy signals in this condition. Bottom, Bar graph summarizes population averaged neuronal sensitivities in this condition, as well as the average of this latter theoretical prediction.

was unexpectedly prevented from moving. As a result, although a head movement command was produced, the monkey did not experience the expected neck proprioceptive feedback. Accordingly, we next tested whether an otolith input suppression signal might be gated only in conditions where the actual activation of neck proprioceptors matches the expected proprioceptive feedback. To do this, we compared the neuronal encoding of translational motion in two conditions.

First, we recorded neuronal activity in the head-unrestrained monkey as we applied passive whole-body translation. Figure $5 \mathrm{~A}$ illustrates the response of a neuron during concurrent active (red trace) and passively applied (blue trace) translation. Note that the stimulus to the otolith system (i.e., head-in-space acceleration denoted by the black trace) equals the sum of the passively applied (blue arrow in schemas) and voluntarily generated translation (red arrow in schemas). The example neuron was typical of our population in that it selectively encoded the passive component of translation (compare superimposed passive-only prediction (blue dashed trace) and total vestibular prediction (thin black trace)). Accordingly, the response to vestibular stimulation 
A Active Head on Body + Passive Whole Body

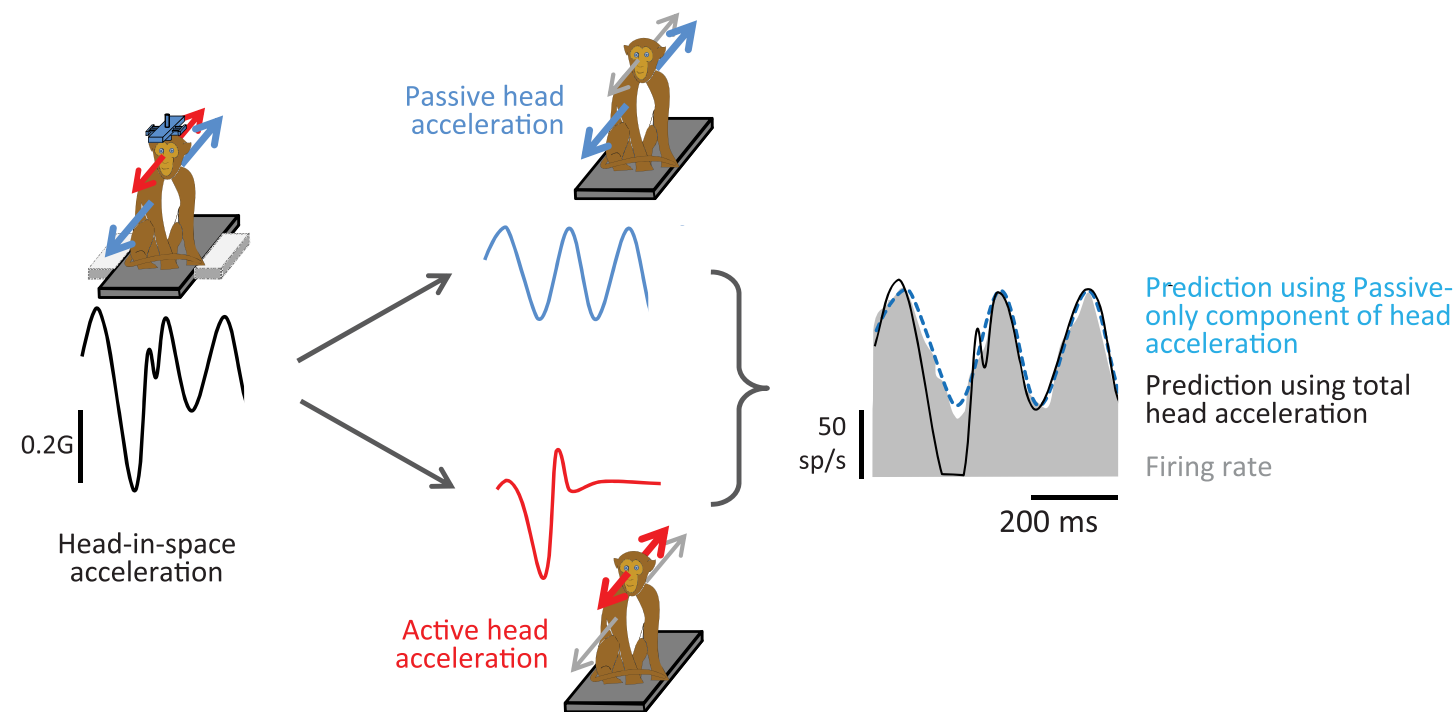

B

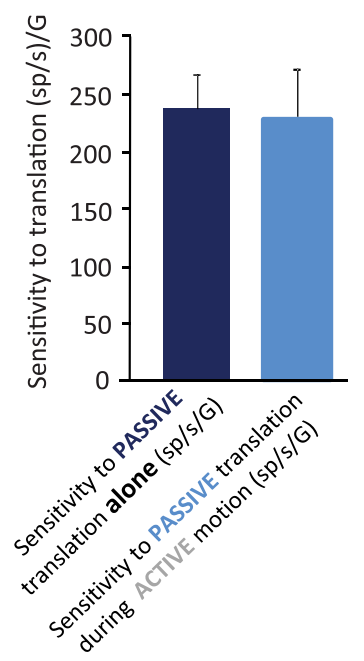

C

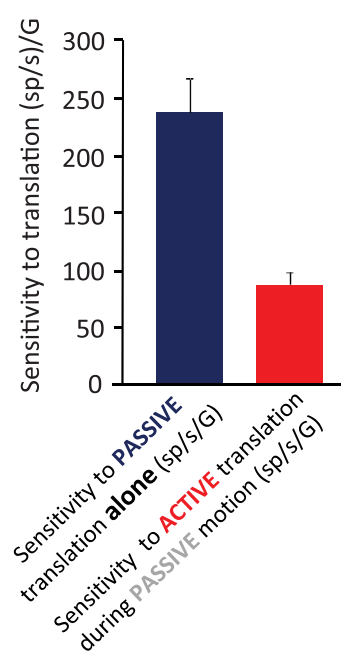

D muscle

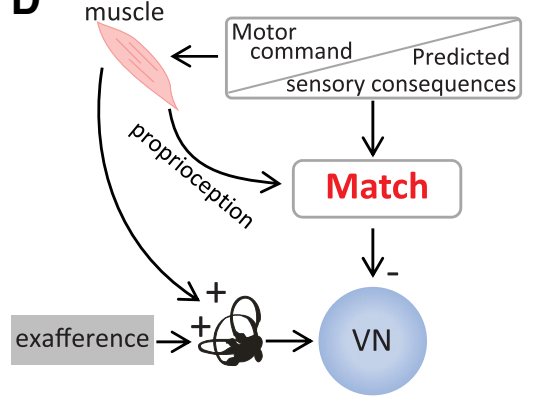

Figure 5. A, Neuronal responses to simultaneous passive and active head motion when sensory expectations and feedback correspond. Black traces represent total head-in-space acceleration. Blue traces represent the component of the head motion that was passively applied. Red traces represent the component of the head motion that was actively generated. Two predictions are superimposed on the recorded firing rates: (1) the total vestibular prediction which assumes unattenuated sensitivity to the total head motion (black trace) and (2) the passive-only prediction which assumes unattenuated preferential encoding of the passive component of the head motion (blue dashed line). When active and passive translation occurred concurrently, the neuron selectively encoded the passive component ( $\boldsymbol{A}$, compare black and blue dashed fits). $\boldsymbol{B}, \boldsymbol{C}$, Summary of population responses during combined stimulation. Neuronal sensitivities to passive whole-body translation were comparable when applied alone or simultaneously during the production of active head-on-body translations $(\boldsymbol{B})$. In contrast, neuronal responses to the active component of the head motion were consistently attenuated (C).D, A model schematic formalizing the hypothesis that a match between the brain's expectation of the sensory consequences of active translation and actual sensory feedback is required to gate in the otolith cancellation signal.

produced by the head-in-space motion generated by the monkey's own voluntary movement was selectively suppressed.

Figure $5 B, C$ summarizes these findings for the sample of neurons tested in this condition $(n=10)$. Neuronal sensitivities to passive motion were comparable when applied alone or when active head translations were generated concurrently [Fig. $5 B$; $254(\mathrm{sp} / \mathrm{s}) / \mathrm{G} \pm 31 \mathrm{vs} 253(\mathrm{sp} / \mathrm{s}) / \mathrm{G} \pm 29 ; p=0.83]$. In contrast, neurons showed attenuated modulation to active motion that occurred during passive stimulation (86 (sp/s)/G \pm 10 ; Fig. $5 C$ ), and the reduction in neuronal sensitivity was comparable to that observed when active motion was generated alone (mean attenuation: $62 \% \pm 6$ vs $61 \% \pm 7 ; p=0.71)$. Thus, these findings suggest that this group of vestibular nuclei neurons is able to distinguish between active and passive components of head translation if the actual activation of neck proprioceptors matches the expected proprioceptive feedback. This proposal is shown schematically in Figure 5D.

In the experiment above, the passively applied stimulation moved the entire head and body together relative to space and thus did not alter the relationship between the brain's prediction of the sensory consequence of the voluntarily produced head-onbody motion and the actual activation of neck proprioceptors. What would happen if externally applied motion not only stimulated the otolith system, but also perturbed the relationship between the neck motor command and neck sensory feedback? To address this question, we recorded from the same $(n=10)$ neurons during a second condition in which we applied passive head motion directly to the monkey's head during an active head movement. Figure $6 A$ illustrates the response of the example neuron during concurrent passively applied and actively generated 


\section{A Active Head on Body + Passive Head perturbation}

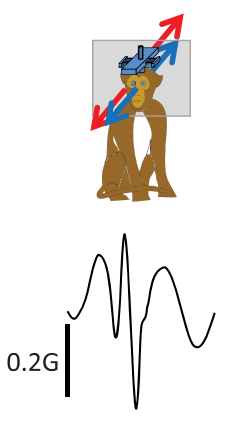

Head-in-space acceleration
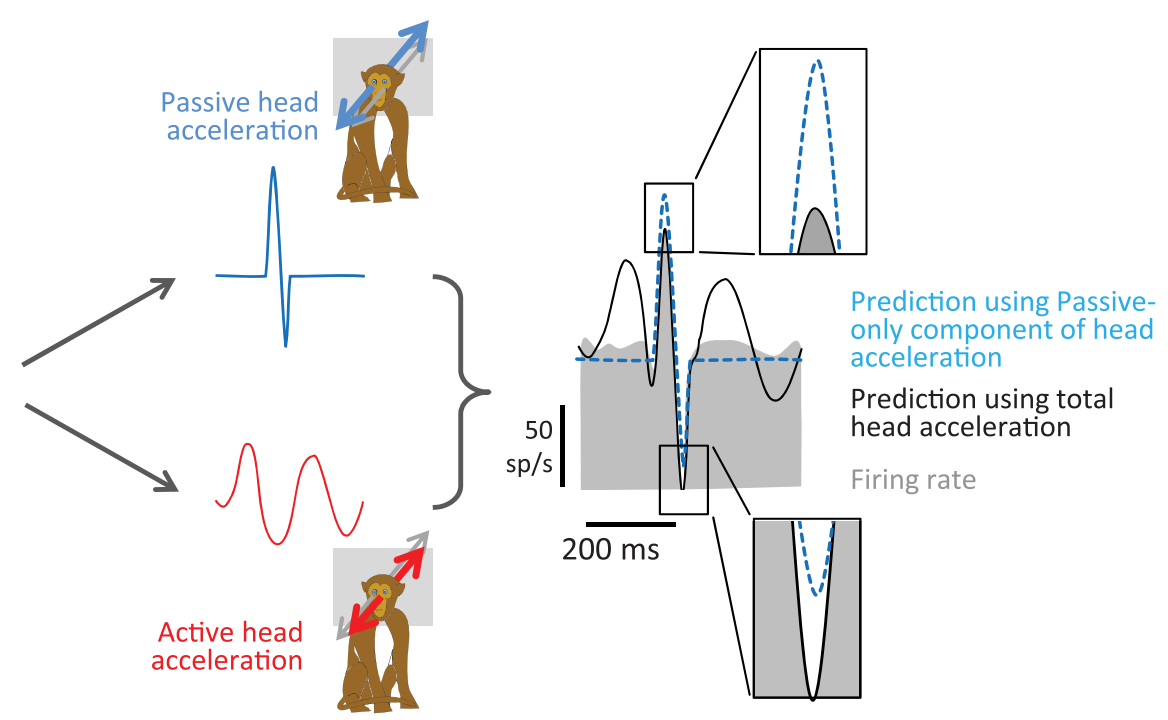

B

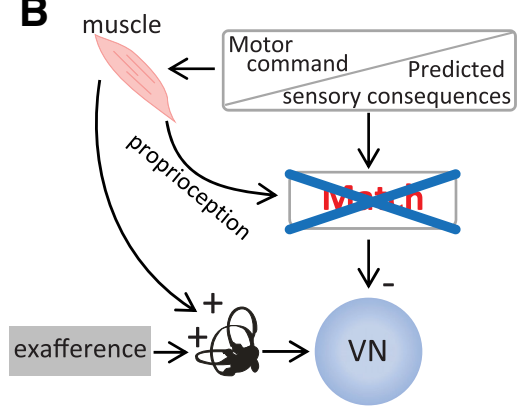

C

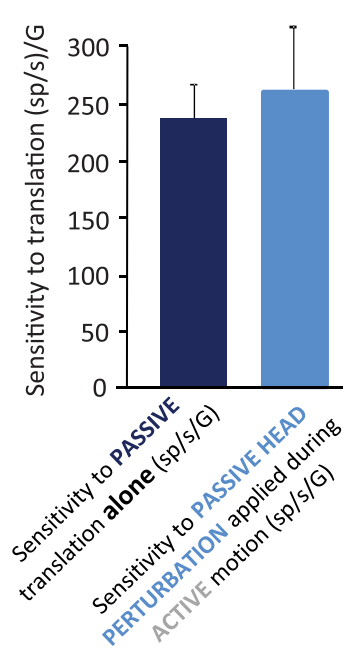

D

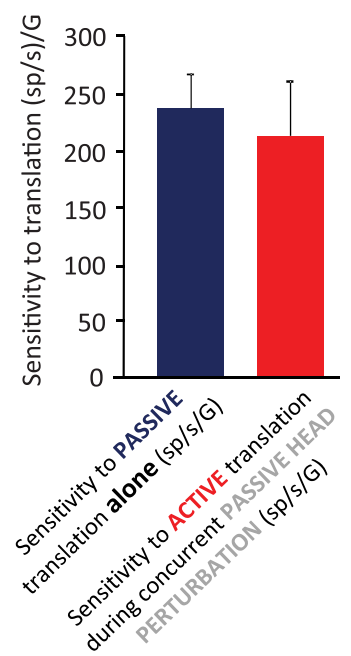

Figure 6. Neuronal responses to simultaneous passive and active head motion when proprioceptive feedback and sensory expectations do not correspond. $\boldsymbol{A}$, Black traces represent the head-in-space acceleration. Blue traces represent the component of the head motion produced by the passive head perturbation (see Materials and Methods). Red traces represent the component of the head motion that was actively generated. Two predictions are superimposed on the recorded firing rates: (1) the total vestibular prediction, which assumes unattenuated sensitivity to the total head motion (black trace), and (2) the passive-only prediction which assumes unattenuated preferential encoding of the passive component of the head motion (blue dashed line). In this condition, the neuron was not able to discriminate the active and passive component of head motion and instead encoded all vestibular information (right, insets, compare black solid and blue dashed traces). $B$, A model schematic formalizing this experiment in which a match between the brain's expectation of the sensory consequences of active translation and the actual sensory feedback does not occur during active translation. $\boldsymbol{C}, \boldsymbol{D}$, Summary of population responses during combined stimulation. Sensitivities to passive motion applied alone or simultaneously with active head translation were comparable (C). Sensitivities to the active component of the motion were not attenuated when produced during simultaneously passive head-on-body perturbations (D).

head-on-body translation. Because in this condition passive translation is the result of an applied head-on-body movement, the sensory expectation based on the motor command no longer matches the resultant sensory feedback from the actual head movement (Fig. 6B). Consistent with our initial hypothesis, we found that neurons no longer distinguish between active and passive components of head motion. Instead, the example neuron was typical in that it robustly encoded active as well as passive translation [Fig. 6A; superimposed passive-only prediction (blue dashed trace) and total vestibular prediction (thin black trace)]. Note that when the acceleration was positive during perturbation, the simultaneous active acceleration was negative causing the passive-only prediction to overestimate the neuronal response (Fig. 6A, top, inset). Figure 6C,D summarizes these find- ings for our sample of neurons. Notably, response sensitivities to head perturbations were comparable when applied alone and when active head translations were generated concurrently [Fig. $6 C ; 236(\mathrm{sp} / \mathrm{s}) / \mathrm{G} \pm 30 \mathrm{vs} 258(\mathrm{sp} / \mathrm{s}) / \mathrm{G} \pm 55 ; p=0.69]$. Strikingly, neuronal sensitivities to both the active and passive components of motion were the same as for the condition in which passive motion was applied alone [sensitivities to head perturbation alone: $236(\mathrm{sp} / \mathrm{s}) / \mathrm{G} \pm 30$; head perturbations when active head translations were generated concurrently: 258 (sp/s)/G \pm 55 ; active head translations during head perturbations: $212 \mathrm{sp} / \mathrm{s} / \mathrm{g} \pm 49$; $p>0.05$ for both active and passive components; Figure $6 D]$.

Thus, signals related to neck motor commands do play an important role in suppressing otolith inputs at the level of the vestibular nuclei. Together, the findings shown in Figures 5 and 6 
suggest that an otolith input suppression signal is sent to the vestibular nuclei during conditions where the actual activation of neck proprioceptors matches the proprioceptive feedback expected as a consequence of self-generated head translation consistent, with the model schematics shown in Figures $5 D$ and $6 B$. As a result, neurons are able to dissociate the active and passive component of translation in conditions when neck proprioceptive feedback matches the expected sensory consequences (Fig. 5).

\section{Discussion}

Here we show for the first time that the responses of otolith driven neurons at the first central stage of processing (i.e., the VO neurons in the vestibular nuclei) are attenuated during active head translations. This is in striking contrast to their afferent inputs, which similarly encode active and passive linear motion (Jamali et al., 2009). The mechanism underlying the cancellation of otolith input during active motion does not affect other neuronal firing characteristics (i.e., baseline firing rates, tuning ratio, maximal vector orientation). To gain further insight, we evaluated whether neurons responded to extra-vestibular cues that were present during active but not passive motion (i.e., neck proprioception, efference copy signals, but not visual since experiments were performed in darkness). Neither cue alone directly influenced neuronal responses. Instead, we found that an otolithcancellation signal is only produced in conditions where sensory feedback from proprioception matches the motor-based expectation. Specifically, neurons at the first central stage of otolith processing selectively encode translation when there is a mismatch between proprioceptive sensory feedback and the motorbased expectation. We suggest our results have important implications for the control of posture and accurate motor responses, as well as understanding the brain's strategy for computing an estimate of self-motion during active heading.

\section{Encoding passive versus active translation: response attenuation and neuronal tuning}

To date, surprisingly few studies have characterized the responses of primate vestibular neurons during translation. Our population of translation-sensitive VO neurons showed distributed tuning for passive translations, and a given cell's directional preference to active motion corresponded well to that observed for passive motion. Specifically, although neuronal responses to active translation were markedly attenuated, the overall shape of the tuning curve and the orientation at which responses were maximal remained unchanged. These neurons most likely send vestibular information to the ascending vestibular thalamocortical pathways (for review, see Angelaki and Cullen, 2008). Target neurons in the vestibular thalamus also display distributed tuning to passive translations (Marlinski and McCrea, 2008; Meng and Angelaki, 2010). In contrast, neurons in the dorsal medial superior temporal area (MSTd) of visual cortex appear to respond with a lateral bias to passive translations (Gu et al., 2006; Takahashi et al., 2007). Thus, the pooled MSTd population response is most precise for naso-occipital motion (Gu et al., 2010); a bias consistent with heading perception in humans and macaques (Gu et al., 2010). Further studies will be required to determine whether this bias is also present at the cortical level during active motion, and/or could potentially be modified as a result of training or experience (e.g., the changes in vestibular nuclei tuning observed after sustained tilt; Eron et al., 2008, 2009).

\section{The integration of vestibular and extra-vestibular cues underlies cancellation of otolith input}

The encoding of self-motion information is inherently multimodal, and a distinguishing feature of early vestibular processing is the integration of self-motion cues at the first stage of central processing. However, the strategy by which this is accomplished can vary even within a single genus. For example, stimulation of neck proprioceptors alone via rotation influences VO neuron activity in Macaca fascicularis (Sadeghi et al., 2009), but not Macaca mulatta (i.e., rhesus monkey; Roy and Cullen, 2001a, 2004). In the present study, we similarly found that passive stimulation of proprioceptors produced by translations of the body relative to the head (Fig. $4 B$ ) has no effect on VO neuron activity in rhesus monkey. Furthermore, the production of a motor command alone cannot account for the observed response attenuation to actively produced head translations (Fig. 4C). Thus, otolith cancellation is mediated by a mechanism more sophisticated than that envisioned by von Holst and Mittelstaedt (1950) in which the brain simply computes the difference between the total sensory input and a motor-based estimate of the sensory input resulting from self-produced stimulation (termed reafference) to calculate the externally applied sensory stimulation (termed exafference).

In our experiments, otolith cancellation only occurred in conditions where the actual activation of neck proprioceptors matched the brain's expectation (i.e., internal model) of the sensory consequence of head motion. Specifically, neurons preferentially encoded passive head motion when active and passive translation occurred simultaneously, if stimulation of neck proprioceptors was solely the result of the active translation (Fig. $5 D$ ). However, neurons were no longer able to make this distinction when proprioceptors were stimulated by both the passive and active components of simultaneous motion (Fig. 6B). These results are thus consistent with the theoretical model originally proposed by Roy and Cullen (2004) to account for the cancellation of semicircular canal inputs during active rotations (i.e., reafferent canal inputs). Accordingly our results suggest a general framework by which the brain preferentially encodes unexpected vestibular (i.e., both semicircular canal and otolith) inputs during self-motion.

The present study focused exclusively on VO neurons, however there are two other main classes of vestibular nuclei neurons; Position-vestibular-pause (PVP) and Floccular target neurons (FTNs). Rather than contributing to postural control and selfmotion perception, these neurons mediate the vestiblo-ocular reflex (for review, see Cullen, 2012). Our prior studies have shown that PVPs and FTNs do not distinguish between active and passive rotations. Instead, their responses are comparable whenever the behavioral goal is to stabilize gaze relative to space. Accordingly, we would predict that these neurons similarly do not distinguish between active and passive head translations.

\section{Functional implications of otolith input cancellation: postural control and self-motion perception}

The ability to keep track of where we are in relation to where we are heading is essential for accurate motor control and perception. Notably, the neurons that were the focus of the present study project to the spinal cord to mediate vestibulo-spinal reflex pathways (for review, see Cullen, 2011). During voluntary translations, postural responses produced by these reflexes would produce stabilizing commands that would be counterproductive. We found, however, that by integrating proprioceptive and motor related cues with otolith information, neurons preferentially 
encode unexpected translations thereby providing a solution to ensure robust postural responses to unexpected vestibular stimuli. Thus, our results establish that otolith-spinal reflexes are not hard-wired but are instead selectively gated, such that their efficacy to otolith inputs can be preferentially reduced for actively generated translations.

The perception of self-motion that does not rely upon acquiring positional information by directly sensing features of the external environment (e.g., viewing a landmark at a known location) is referred to as path integration or dead reckoning (for review, see Loomis et al., 1999; McNaughton et al., 2006). The ability to update our representation of body position in the absence of such visual input (e.g., walking in the dark or without salient visual landmarks) depends on the integration of actively generated signals (i.e., motor efference copy and proprioceptive cues) with otolith information (Frissen et al., 2011; Jürgens and Becker, 2006). The neurons characterized in this study are a likely origin (via the thalamus) of vestibular input to cortical areas responsible for perception (for review, see Angelaki and Cullen, 2008). Thus, at first glance, our findings appear to suggest that the heading and navigational signals encoded in higher-level areas are attenuated during active motion. However, heading is robustly perceived during active motion even in the absence of vision (Mittelstaedt and Glasauer, 1991, 1992). One possibility is that the brain relies solely on the residual vestibular information available from the subset of neurons that show less attenuation to active motion to compute an internal estimate of self-motion. A more likely possibility is that the further integration of extravestibular cues is required.

Indeed, self-motion cues derived from proprioceptive and/or motor efference copy signals appear to influence the responses of head direction cells of the limbic system (Wiener et al., 2002). The signal encoded by head direction cells is generally thought to be generated by an attractor network (Skaggs et al., 1995; McNaughton et al., 2006; for review, see Clark and Taube, 2012) updated by allocentric head direction information through the integration of head-in-space velocity signals (of vestibular origin; Stackman and Taube, 1997; Muir et al., 2009; Yoder and Taube, 2009; Ravassard et al., 2013) to ensure that the encoded and actual head directions stay in register; but other idiothetic selfmotion cues are likely important. In addition, head-direction cell responses appear to anticipate head motion (Taube and Bassett, 2003); an effect believed to reflect the high-pass characteristics of vestibular nuclei neurons (van der Meer et al., 2007). Anticipatory responses are more pronounced during passive than active head motion (Bassett et al., 2004), and we speculate that this difference may reflect the attenuation of $\mathrm{VO}$ response during active rotation.

To date, prior studies describing the information encoded by other cortical areas, which likely contribute to the perception of self-motion (e.g., parieto-insular vestibular cortex, MSTd, areas 2v and 3a; Grüsser et al., 1990a,b; Fasold et al., 2008; for review, see Angelaki et al., 2011; Lopez and Blanke, 2011), have considered only passive stimuli. Thus, it remains to be determined whether these areas distinguish actively generated from passive head movements. Further experiments will be required to understand how the brain integrates extra-vestibular cues with the attenuated vestibular signal to compute a robust estimate of heading during active self-motion.

\section{References}

Angelaki DE (1993) Generation of two-dimensional spatial and temporal properties through spatiotemporal convergence between one- dimensional neurons. IEEE Trans Biomed Eng 40:686-692. CrossRef Medline

Angelaki DE, Cullen KE (2008) Vestibular system: the many facets of a multimodal sense. Ann Rev Neurosci 31:125-150. CrossRef Medline

Angelaki DE, Dickman JD (2000) Spatiotemporal processing of linear acceleration: primary afferent and central vestibular neuron responses. J Neurophysiol 84:2113-2132. Medline

Angelaki DE, Gu Y, Deangelis GC (2011) Visual and vestibular cue integration for heading perception in extrastriate visual cortex. J Physiol 589: 825-833. CrossRef Medline

Bassett JP, Zugaro MB, Muir GM, Golob EJ, Muller RU, Taube JS (2004) Passive movements of the head do not abolish anticipatory firing properties of head direction cells. J Neurophysiol 93:1304-1316. CrossRef Medline

Becker W, Nasios G, Raab S, Jürgens R (2002) Fusion of vestibular and podokinesthetic information during self-turning towards instructed targets. Exp Brain Res 144:458-474. CrossRef Medline

Berthoz A, Israël I, Georges-Francois P, Grasso R, Tsuzuku T (1995) Spatial memory of body linear displacement: what is being stored? Science 269: 95-98. CrossRef Medline

Brooks JX, Cullen KE (2009) Multimodal integration in rostral fastigial nucleus provides an estimate of body movement. J Neurosci 29:1049910511. CrossRef Medline

Cherif S, Cullen KE, Galiana HL (2008) An improved method for the estimation of firing rate dynamics using an optimal digital filter. J Neurosci Methods 173:165-181. CrossRef Medline

Clark BJ, Taube JS (2012) Vestibular and attractor network basis of the head direction cell signal in subcortical circuits. Front Neural Circuits 6:7. CrossRef Medline

Cullen KE (2011) The neural encoding of self-motion. Curr Opin Neurobiol 21:587-595. CrossRef Medline

Cullen KE (2012) The vestibular system: multimodal integration and encoding of self-motion for motor control. Trends Neurosci 35:185-196. CrossRef Medline

Cullen KE, McCrea RA (1993) Firing behavior of brain stem neurons during voluntary cancellation of the horizontal vestibuloocular reflex: I. Secondary vestibular neurons. J Neurophysiol 70:828-843. Medline

Cullen KE, Rey CG, Guitton D, Galiana HL (1996) The use of system identification techniques in the analysis of oculomotor burst neuron spike train dynamics. J Comput Neurosci 3:347-368. CrossRef Medline

Dickman JD, Angelaki DE (2002) Vestibular convergence patterns in vestibular nuclei neurons of alert primates. J Neurophysiol 88:3518-3533. CrossRef Medline

Eron JN, Cohen B, Raphan T, Yakushin SB (2008) Adaptation of orientation vectors of otolith-related central vestibular neurons to gravity. J Neurophysiol 100:1686-1690. CrossRef Medline

Eron JN, Cohen B, Raphan T, Yakushin SB (2009) Adaptation of orientation of central otolith-only neurons. Ann N Y Acad Sci 1164:367-371. CrossRef Medline

Fasold O, Heinau J, Trenner MU, Villringer A, Wenzel R (2008) Proprioceptive head posture-related processing in human polysensory cortical areas. Neuroimage 40:1232-1242. CrossRef Medline

Frissen I, Campos JL, Souman JL, Ernst MO (2011) Integration of vestibular and proprioceptive signals for spatial updating. Exp Brain Res 212:163176. CrossRef Medline

Fuchs AF, Kimm J (1975) Unit activity in vestibular nucleus of the alert monkey during horizontal angular acceleration and eye movement. J Neurophysiol 38:1140-1161. Medline

Gibson JJ (1950) The perception of visual surfaces. Am J Psychol 63:367384. CrossRef Medline

Glasauer S, Amorim MA, Vitte E, Berthoz A (1994) Goal-directed linear locomotion in normal and labyrinthine-defective subjects. Exp Brain Res 98:323-335. Medline

Glasauer S, Amorim MA, Viaud-Delmon I, Berthoz A (2002) Differential effects of labyrinthine dysfunction on distance and direction during blindfolded walking of a triangular path. Exp Brain Res 145:489-497. CrossRef Medline

Grasso R, Glasauer S, Georges-François P, Israël I (1999) Replication of passive whole-body linear displacements from inertial cues: facts and mechanisms. Ann N Y Acad Sci 871:345-366. CrossRef Medline

Grüsser OJ, Pause M, Schreiter U (1990a) Localization and responses of 
neurones in the parieto-insular vestibular cortex of awake monkeys (Macaca fascicularis). J Physiol 430:537-557. Medline

Grüsser OJ, Pause M, Schreiter U (1990b) Vestibular neurones in the parieto-insular cortex of monkeys (Macaca fascicularis): visual and neck receptor responses. J Physiol 430:559-583. Medline

Gu Y, Watkins PV, Angelaki DE, DeAngelis GC (2006) Visual and nonvisual contributions to three-dimensional heading selectivity in the medial superior temporal area. J Neurosci 26:73-85. CrossRef Medline

Gu Y, Fetsch CR, Adeyemo B, Deangelis GC, Angelaki DE (2010) Decoding of MSTd population activity accounts for variations in the precision of heading perception. Neuron 66:596-609. CrossRef Medline

Guedry FE Jr, Harris CS (1963) Labyrinthine function related to experiments on the parallel swing: project Mr005.13-6001, Subtask 1, Rep No. 86. Res Rep US Nav Sch Aviat Med 1-32. Medline

Hayes AV, Richmond BJ, Optican LM (1982) A UNIX-based multiple process system for real-time data acquisition and control. WESCON Conf Proc 2:1-10.

Israël I, Berthoz A (1989) Contribution of the otoliths to the calculation of linear displacement. J Neurophysiol 62:247-263. Medline

Israël I, Chapuis N, Glasauer S, Charade O, Berthoz A (1993) Estimation of passive horizontal linear whole-body displacement in humans. J Neurophysiol 70:1270-1273. Medline

Israël I, Grasso R, Georges-Francois P, Tsuzuku T, Berthoz A (1997) Spatial memory and path integration studied by self-driven passive linear displacement: I. Basic properties. J Neurophysiol 77:3180-3192. Medline

Ivanenko YP, Grasso R (1997) Integration of somatosensory and vestibular inputs in perceiving the direction of passive whole-body motion. Brain Res Cogn Brain Res 5:323-327. CrossRef Medline

Jamali M, Sadeghi SG, Cullen KE (2009) Response of vestibular nerve afferents innervating utricle and saccule during passive and active translations. J Neurophysiol 101:141-149. CrossRef Medline

Jürgens R, Becker W (2006) Perception of angular displacement without landmarks: evidence for Bayesian fusion of vestibular, optokinetic, podokinesthetic, and cognitive information. Exp Brain Res 174:528-543. CrossRef Medline

Loomis JM, Klatzky RL, Golledge RG, Philbeck JW (1999) Human navigation by path integration. In: Wayfinding: cognitive mapping and spatial behaviour (Golledge RG, Philbeck JW, eds), pp 125-151. Johns Hopkins UP: Baltimore.

Lopez C, Blanke O (2011) The thalamocortical vestibular system in animals and humans. Brain Res Rev 67:119-146. CrossRef Medline

Marlinski V, McCrea RA (2008) Activity of ventroposterior thalamus neurons during rotation and translation in the horizontal plane in the alert squirrel monkey. J Neurophysiol 99:2533-2545. CrossRef Medline

McCrea RA, Gdowski GT, Boyle R, Belton T (1999) Firing behavior of vestibular neurons during active and passive head movements: vestibulospinal and other non-eye-movement related neurons. J Neurophysiol 82: 416-428. Medline

McNaughton BL, Battaglia FP, Jensen O, Moser EI, Moser MB (2006) Path integration and the neural basis of the "cognitive map." Nat Rev Neurosci 7:663-678. CrossRef Medline

Meng H, Angelaki DE (2010) Responses of ventral posterior thalamus neurons to three-dimensional vestibular and optic flow stimulation. J Neurophysiol 103:817-826. CrossRef Medline

Mittelstaedt ML, Glasauer S (1991) Idiothetic navigation in gerbils and humans. Zool Jahrb Physiol 95:427-435.

Mittelstaedt HL, Glasauer S (1992) The contribution of inertial and substratal information to the perception of linear displacement. In: 17th
Barany Society Meeting (Jerabeck HKJ, ed), pp 102-105. Bratislava: Slovakian Academy of Sciences.

Muir GM, Brown JE, Carey JP, Hirvonen TP, Della Santina CC, Minor LB, Taube JS (2009) Disruption of the head direction cell signal after occlusion of the semicircular canals in the freely moving chinchilla. J Neurosci 29:14521-14533. CrossRef Medline

Ravassard P, Kees A, Willers B, Ho D, Aharoni D, Cushman J, Aghajan ZM, Mehta MR (2013) Multisensory control of hippocampal spatiotemporal selectivity. Science 340:1342-1346. CrossRef Medline

Roy JE, Cullen KE (1998) A neural correlate for vestibulo-ocular reflex suppression during voluntary eye-head gaze shifts. Nat Neurosci 1:404-410. CrossRef Medline

Roy JE, Cullen KE (2001a) Passive activation of neck proprioceptive inputs does not influence the discharge patterns of vestibular nuclei neurons. Ann N Y Acad Sci 942:486-489. CrossRef Medline

Roy JE, Cullen KE (2001b) Selective processing of vestibular reafference during self-generated head motion. J Neurosci 21:2131-2142. Medline

Roy JE, Cullen KE (2004) Dissociating self-generated from passively applied head motion: neural mechanisms in the vestibular nuclei. J Neurosci 24:2102-2111. CrossRef Medline

Sadeghi SG, Chacron MJ, Taylor MC, Cullen KE (2007) Neural variability, detection thresholds, and information transmission in the vestibular system. J Neurosci 27:771-781. CrossRef Medline

Sadeghi SG, Goldberg JM, Minor LB, Cullen KE (2009) Effects of canal plugging on the vestibuloocular reflex and vestibular nerve discharge during passive and active head rotations. J Neurophysiol 102:2693-2703. CrossRef Medline

Scudder CA, Fuchs AF (1992) Physiological and behavioral identification of vestibular nucleus neurons mediating the horizontal vestibuloocular reflex in trained rhesus monkeys. J Neurophysiol 68:244-264. Medline

Skaggs WE, Knierim JJ, Kudrimoti HS, McNaughton BL (1995) A model of the neural basis of the rat's sense of direction. Adv Neural Inf Process Syst 7:173-180. Medline

Stackman RW, Taube JS (1997) Firing properties of head direction cells in the rat anterior thalamic nucleus: dependence on vestibular input. J Neurosci 17:4349-4358. Medline

Sylvestre PA, Cullen KE (1999) Quantitative analysis of abducens neuron discharge dynamics during saccadic and slow eye movements. J Neurophysiol 82:2612-2632. Medline

Takahashi K, Gu Y, May PJ, Newlands SD, DeAngelis GC, Angelaki DE (2007) Multimodal coding of three-dimensional rotation and translation in area MSTd: comparison of visual and vestibular selectivity. J Neurosci 27:9742-9756. CrossRef Medline

Taube JS, Bassett JP (2003) Persistent neural activity in head direction cells. Cereb Cortex 13:1162-1172. CrossRef Medline

van der Meer MA, Knierim JJ, Yoganarasimha D, Wood ER, van Rossum MC (2007) Anticipation in the rodent head direction system can be explained by an interaction of head movements and vestibular firing properties. J Neurophysiol 98:1883-1897. CrossRef Medline

Von Holst E, Mittelstaedt H (1950) Das Reafferenzprinzip. Naturwissenschaften 37:464-476. CrossRef

Wiener SI, Berthoz A, Zugaro MB (2002) Multisensory processing in the elaboration of place and head direction responses by limbic system neurons. Brain Res Cogn Brain Res 14:75-90. CrossRef Medline

Worchel P (1952) The role of the vestibular organs in space orientation. J Exp Psychol 44:4-10. CrossRef Medline

Yoder RM, Taube JS (2009) Head direction cell activity in mice: robust directional signal depends on intact otolith organs. J Neurosci 29:10611076. CrossRef Medline 